\title{
Variations of VLF radio signals and atmospherics during the deep earthquake with $M=8.2$ occurred on 24 May 2013 near Kamchatka peninsula
}

\author{
Viktor A. Mullayarov ${ }^{1^{*}}$, Gennady I. Druzhin ${ }^{2}$, Vyacheslav V. Argunov $^{1}$, \\ Larisa M. Abzaletdinova', Aleksander N. Mel'nikov \\ ${ }^{1}$ Yu.G. Shafer Institute of Cosmophysical Research and Aeronomy SB of RAS, Yakutsk, Russia; \\ *Corresponding Author: mullayarov@ikfia.sbras.ru \\ ${ }^{2}$ Institute of Cosmophysical Research and Radiowaves Propagation FEB of RAS, Paratunka, Russia
}

Received 6 January 2014; revised 6 February 2014; accepted 13 February 2014

Copyright (C) 2014 Viktor A. Mullayarov et al. This is an open access article distributed under the Creative Commons Attribution License, which permits unrestricted use, distribution, and reproduction in any medium, provided the original work is properly cited. In accordance of the Creative Commons Attribution License all Copyrights (C) 2014 are reserved for SCIRP and the owner of the intellectual property Viktor A. Mullayarov et al. All Copyright (C) 2014 are guarded by law and by SCIRP as a guardian.

\section{ABSTRACT}

To detect seismic disturbances in the lower ionosphere, we have used the signals of very-lowfrequency radio transmitters and natural radio signals-electromagnetic emission of lightning discharges-atmospherics. On earlier results of observation of atmospherics, it was obtained that the earthquake effects are displayed as weight-hourly amplitude increases on the day of event or within 3 days after them. Possible earthquake precursors are also manifested as one-day (within one to several hours) increases in the amplitude of atmospherics on average 5 12 days before the event. Analysis shows that seismic effects in the amplitude of atmospherics have been observed in the case of sufficiently strong (magnitude $M>4.5$ ) and not very deep (usually no deeper than $\mathbf{5 0} \mathrm{km}$ ) earthquakes. The effects of the events of the earthquake with magnitude of 8.2 occurring in the Sea of Okhotsk on 24.05.13 not far from the Kamchatka Peninsula at a depth of $609 \mathrm{~km}$ considered in this work have shown that even deep earthquakes may have precursors in the form of disturbances in the lower ionosphere.

\section{KEYWORDS}

Earthquake; Precursor; lonosphere; Atmospherics; Radio Signals

\section{INTRODUCTION}

The investigation of manifestations of lithospheric processes in the lower ionosphere is usually done using the signals of very-low-frequency (VLF) or low-frequency (LF) radio transmitters [1-6]. The presence of disturbances in the ionosphere caused by seismic events is confirmed in a number of papers (see, e.g. [7-9]). As it is known, the most sensitive parameter of VLF signal is its phase. Amplitude measurements refer to the rougher methods, although it should be noted that in a number of papers [4,5], the amplitude measurements are used in the search of ionospheric precursors of strong earthquakes (EQs), but those measurements are based on the interference (though on the phase relations) of electromagnetic waves in the vicinity of the terminator.

As an alternative, or supplementing method for detection of seismic disturbances in the ionosphere, the use of natural radio-electromagnetic emission of lightning discharges-atmospherics can be considered [10-12]. Although, unlike radio signals, the atmospherics allow using only amplitude detection methods for ionospheric disturbances, at the same time they allow azimuthal scanning at a single receiving station in a wide sector (in a broad seismic area). From observations of atmospherics passing within the first Fresnel zone over EQ epicenters in Yakutsk $\left(\varphi=62.1^{\circ} \mathrm{N}, \lambda=129.7^{\circ} \mathrm{E}\right)$, it is found that EQ effects were expressed as an increase of hourly average amplitude of atmospherics on the same day or within 3 days after the event. It is noted that due to an unsteady flow of atmospherics, the amplitude averaging should be carried out at least in one-hour interval. Possible precursors of EQ also appeared in one-day (within one to several hours) increases in the amplitude of atmospherics mainly 5 - 12 days before the event. The preliminary analysis shows that the seismic effects in the amplitude 
of atmospherics are observed in the case of sufficiently strong (magnitude $\mathrm{M}>4.5$ ) and not very deep EQs (usually no deeper than $50 \mathrm{~km}$ ). Destructive EQs correspond to the specified conditions (as an example of using the atmospherics for the analysis of disturbances in the ionosphere during strong EQ, we may note the EQ in March 2011 in the vicinity of Honshu island (is known as M9 Tohoku EQ)) [12]. Conditions of not deep and strong magnitude are necessary to transfer sufficient energy of the seismic processes to ionospheric heights that can cause detectable perturbation. At the same time, there can be deep EQs related, of course, to the unique events that may occur in ionospheric disturbances and, consequently, in the amplitude variations of atmospherics. As such events, we consider EQ with magnitude $\mathrm{M}=$ 8.3 occurring on 24.05.2013, in the Okhotsk Sea $(\varphi=$ $54.755^{\circ} \mathrm{N}, \lambda=153.785^{\circ} \mathrm{E}$ ), not far from the coast of the Kamchatka Peninsula. The depth of the EQ was great$608.9 \mathrm{~km}$ [13]. After 14 minutes, the EQ was accompanied by a weak EQ with $\mathrm{M}=5.3$, which occurred 300 $\mathrm{km}$ to the north. At 14:56:29.760 UT, a rather strong EQ with $\mathrm{M}=6.8$ occurred $320 \mathrm{~km}$ to the south.

\section{DATA AND MEASUREMENT TECHNIQUES}

The measurement procedure is sufficiently described in $[11,12]$. Here we should note a weak storm activity in the areas that lie farther off the epicenter of the EQ (the ocean surface in the vicinity of Hawaii and Midway islands) and should "provide” a sufficient flow of atmospherics, which paths above the epicenter would lie within the first Fresnel zone [11,12]. This fact required measurements at two additional stations. One of these stations is located southwest of Yakutsk in the distance of $660 \mathrm{~km}$ (Neryungri), and the second point is on the Kamchatka peninsula (Paratunka, $1960 \mathrm{~km}$ from Yakutsk), i.e. on the other side of the epicenter. Accordingly, sources of signals passing over the epicenter toward Paratunka were thunderstorms in Siberia and further westward. Calibration of the receiving devices was carried out according to the data of global registration of atmospherics by worldwide lightning location network WWLLN [14].

Additionally, analysis of seismic disturbances in the lower ionosphere has been made by measuring the signal amplitude of VLF radio transmitter located in Hawaii (Lualualei, frequency 21,400 Hz). The signals from the south were considered as the "background" radio signals: the transmitter in Japan (Ebino, 22,200 Hz) and transmitter in Australia (North West Cape, 19,800 Hz).

\section{RESULTS}

The epicenter of EQ of 24.05.2013 was located in the Okhotsk Sea, not far from the coast of the Kamchatka Peninsula. The distance from Yakutsk to the epicenter was $1580 \mathrm{~km}$, and azimuth (from the North direction) is 110 degrees, while azimuth of Paratunka is 107 deg., and the distance to Paratunka is $1980 \mathrm{~km}$. Azimuth of the radio transmitter in Hawaii from Yakutsk is $95^{\circ}$, and the distance- $7000 \mathrm{~km}$. The path of radio signal is at a distance of 10 Fresnel zones from the EQ epicenter, that, in general, is beyond the confident detection of a possible region of ionospheric disturbances. The main paths of atmospherics and radio signal are shown in Figure 1.

The day-to-day variations of the average amplitude of atmospherics in near-midnight hours at the receiving point (Yakutsk) are usually chosen to define the seismic ionospheric disturbances [11], because, as known, there is minimal attenuation of signal in the earth-ionosphere waveguide at that time of day. Figure 2(a) shows such variations at 14 UT (24 LT) in Yakutsk for atmospherics falling into the fifth Fresnel zone above the epicenter of EQ in the Okhotsk Sea. The effect of EQ (significant increasing of amplitude on the same day or 1 - 2 days after EQ, [11]) has not been observed. At the same time, in the period preceding the EQ two significant amplitude peaks were observed: on 21.05.13 the amplitude increased 4-fold relative to the background, and on 05.21.13 - 6.6-fold. Such increases are considered by us as EQ precursors, provided that they were observed in the absence of geomagnetic disturbances. It should be noted that a 1.5 - 2.5-fold increase is normally observed. For comparison, Figure 2(b) shows variation of the signal amplitude of VLF radio transmitter in Hawaii, but at another time (in the evening). The picture of variations of radio signal amplitude is almost the same as for the atmospherics; the degree of increase in the amplitude of the signal coincides almost exactly with the increase in the amplitude of atmospherics. However, more detailed analysis showed that the most significant peak (10.05.13) in the amplitude of atmospherics is not statistically justified, since during that hour only a few atmospherics were registered from the necessary direction.

The same amplitude peak in the radio signal was registered almost exclusively at 09 UT. Thus, an abnormally

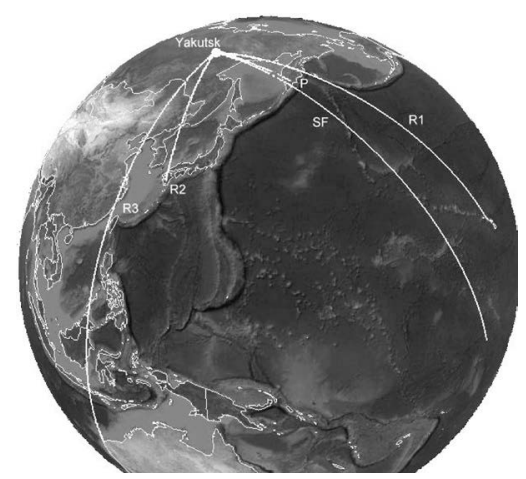

Figure 1. The main paths of atmospherics (path SF) and radio signal (path R1, R2, R3). $\mathrm{P}$-is a Paratunka location. 
high increase in the amplitude of atmospherics and the signal of radio transmitter in the same time interval recorded on 10.05.13 cannot be considered with certainty as a precursor. In this regard, we should consider a more

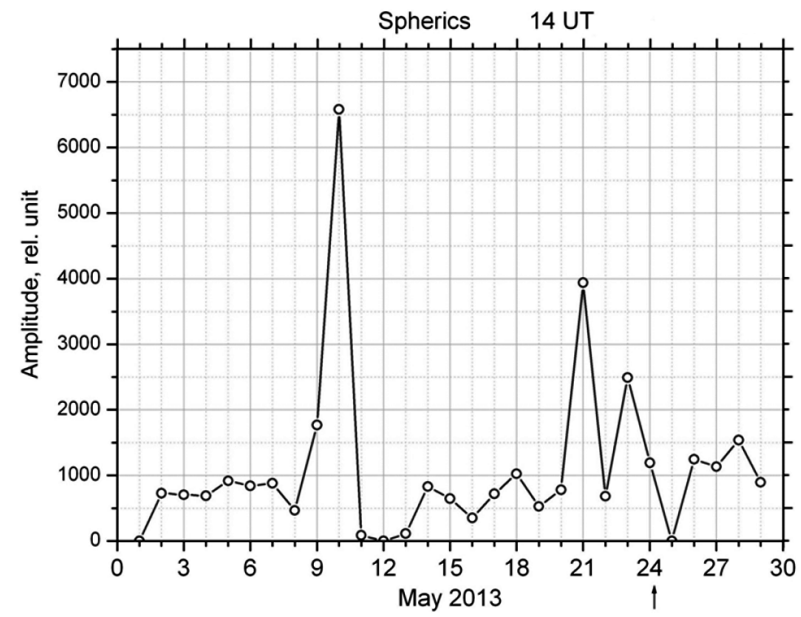

(a) general picture and pay particular attention to the second increase of the amplitude with a maximum on 21.05.13. A more complete picture of amplitude variations (at allhours of the day) is shown in Figure 3. It should be

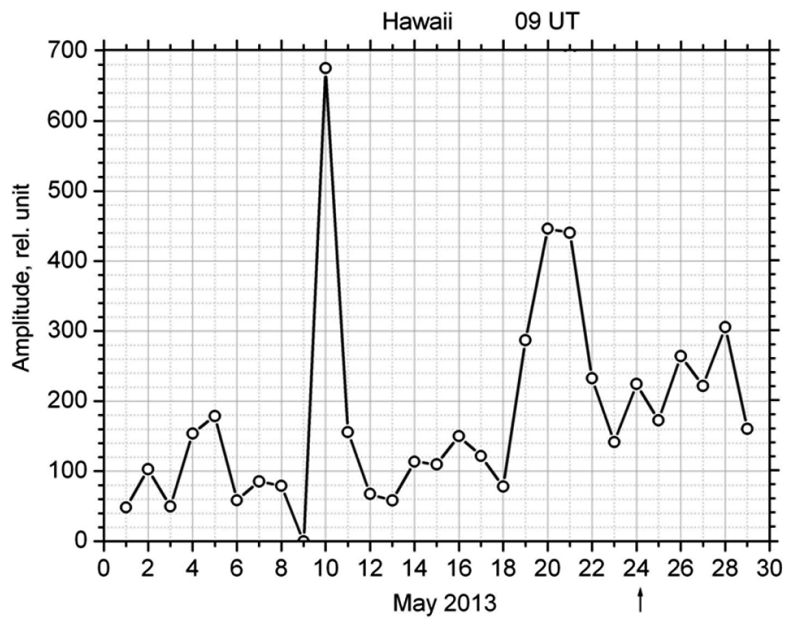

(b)

Figure 2. (a) The day-to-day variations of the average amplitude of atmospherics at 14 UT (24 LT) at the receiving point (Yakutsk); (b) The variation of the signal amplitude of VLF radio transmitter in Hawaii at 09 UT (in the evening in Yakutsk).

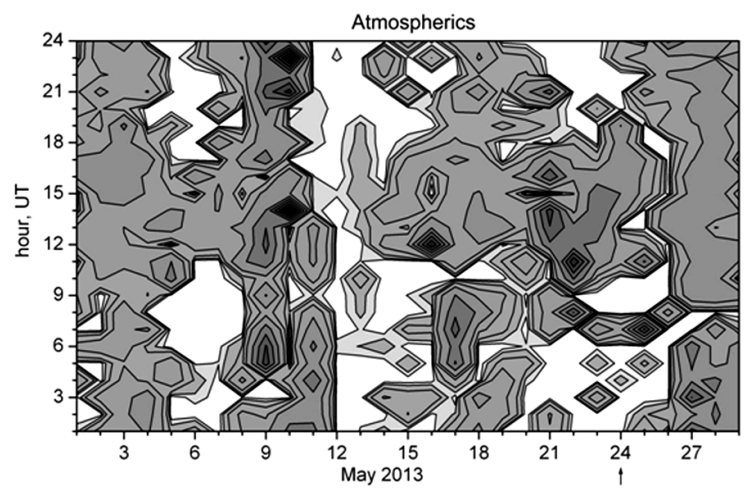

(a)

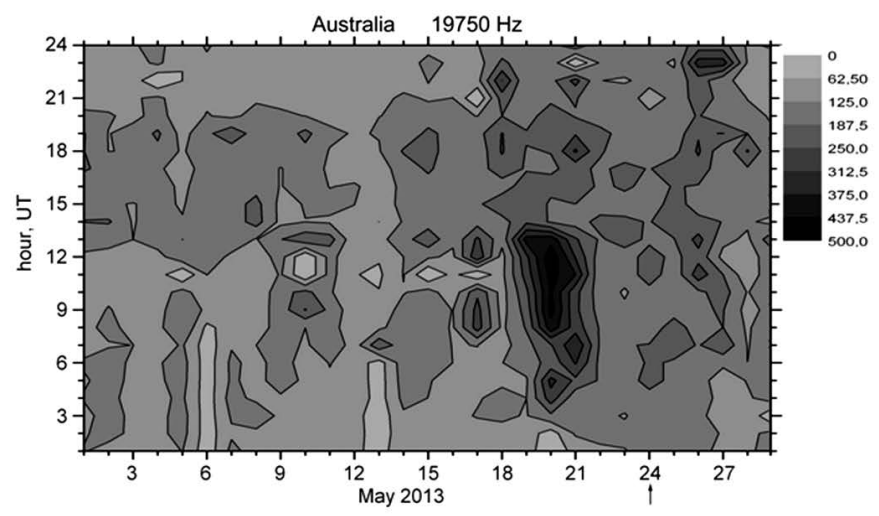

(c)

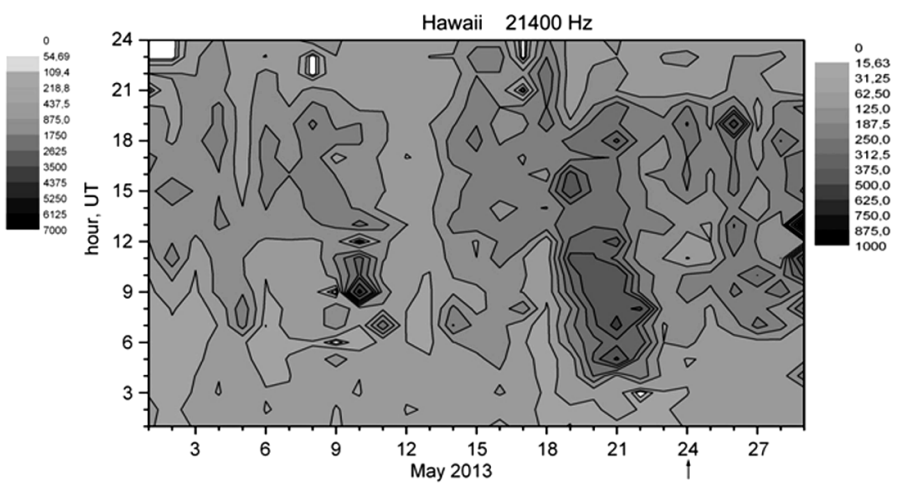

(b)

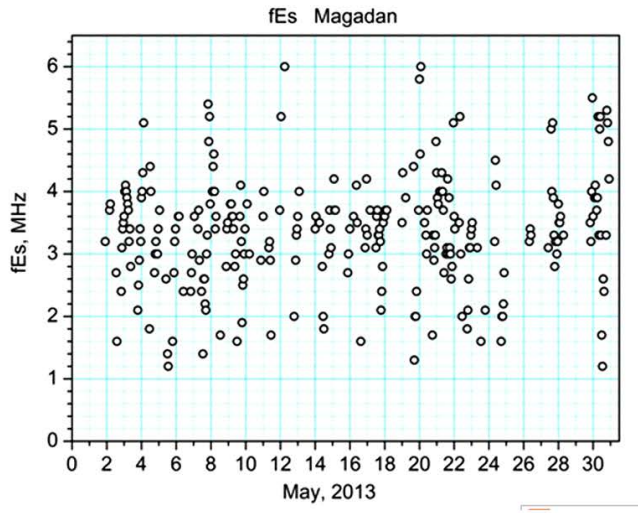

(d)

Figure 3. The amplitude variations of the average amplitude of atmospherics at all hours of the day (a), variations of the radio signal from Hawaii at all hours of the day (b), variations of radio signal of transmitter in Australia (c), and the variations in the frequency of sporadic E-layer fEs in Magadan (d). 
noted that the contour interpolation of the values in constructing the "three-dimensional" picture pattern of variations additionally averages that pattern. Despite the "ragged" picture of amplitude variations of atmospherics, it is clear that on 09-10.05.13 increased amplitude was observed. It is confirmed by relevant variations in the amplitude of the radio signal, although of shorter duration (Figure 3(b)). Recall that the path of the radio signal was somewhat away from the EQ epicenter. A longer increase in the amplitude of the radio signal was recorded on 21.05.13. Also we can note a one-hour 6-fold increase in signal amplitude at 19 UT on 26.05.13. This increase in amplitude easily fits a usually observed 1 - 2day lag of the EQ effect relative to the event [11].

\section{DISCUSSION}

Analysis of the variations in the amplitudes of atmospherics passing within 5 Fresnel zone and radio signal that passes within 10 Fresnel zone relative to the epicenter of the EQ shows that there are two significant amplifications of the signal amplitude before the event, which presumably can be interpreted as ionospheric precursors of EQ. Of special interest is coincidence of the degree of increase in the signal amplitude of atmospherics and the radio signal in Figure 2. However, taking into consideration that both types of signals have been received by the same preamplifier, the same increase in the signal may be due to technical reasons. To exclude this possibility, we can consider the behavior of the signal amplitudes from other azimuthal direction. Azimuthal scan is additional evidence that the increase in signals was connected with the influence of lithospheric processes on the ionosphere (a maximum in the direction of the epicentral area, [11]). Unfortunately, as already noted, the thunderstorm sources in the desired direction in the period under review were weak and could not provide statistically sufficient flow of atmospherics, so let us consider the amplitude variation of radio signals from other azimuths. The two south transmitters were selected: in Japan, 22,200 Hz, and in Australia, 19,800 Hz (see Figure 1). The variations of signal amplitude of Australian radio transmitters at all hours of the day are shown in Figure 3(c). The first thing that draws attention is that the second of the above-mentioned increases in the amplitude, i.e. of 20-21.05.13, has been well manifested in these radio signals. For example, this increase in the range of 09 - 13 UT was 4-fold. As expected, the more significant first peak in the amplitude of the signal from the south transmitters is missing, and therefore, the increase in signals of radio transmitter and thunderstorms from the direction to the epicenter can be apparently interpreted as a precursor of EQ. At the same time, the second, more longer (almost throughout the day) increase in the amplitude of 20-21.05.13 observed in the radio signals received from both the east and the south directions may be attributed to other causes. As is known, one of the most likely causes of ionospheric disturbances can be geomagnetic disturbances.

In VLF radio signals and atmospherics the disturbances were manifested in the lowest layers of the ionosphere: during the day it is a D-layer, and at night-the lower bound of the E-layer. Heterogeneity in the E-layer manifested in the form of sporadic Es-layer may also be due to seismic processes [7-9]. In the case under consideration, at the stations of ionospheric sounding in Paratunka, Kamchatka, that are the nearest to the epicenter (the distance from the epicenter is $390 \mathrm{~km}$ ), the variations in the frequency of sporadic E-layer $\mathrm{f}_{0} \mathrm{Es}$ did not contain the effects of the precursor. However, in Magadan (the distance from the epicenter is $540 \mathrm{~km}$ ) increases of $\mathrm{f}_{0}$ Es were observed on 20-22.05.13 and during night hours UT from 08.05.13 to 09.05.13 (Figure 3(d)), which may be associated with the increase in amplitude of atmospherics received in Yakutsk (Figure 3(a)). A similar pattern of $\mathrm{f}_{0}$ Es was also registered in Khabarovsk.

Variations of Dst-index and Kp-index in May 2013 are shown in Figures 4(a), (b). Geomagnetic disturbances during the month under consideration were weak: Dstindex did not exceed $-50 \mathrm{nT}$. These disturbances occurred on 16-19.05.13 and 24-30.05.13, and maximum values of Kp-index fell on 25.05.13. Taking into account that the second increase of the signal amplitude (2021.05.13) was observed right after an increase in geomagnetic activity and that it was manifested in radio signals received in Yakutsk from different azimuths, this increase could be associated with geomagnetic disturbances. At the same time, in the period of the first and the greatest peak in the signals from the direction to the epicenter, a geomagnetic disturbance was minimal (on 10.05.13 the daily Kp-index value was only 6). Therefore, the geomagnetic disturbances can hardly be the reason for the first peak in atmospherics and radio signals recorded in Yakutsk from the direction to the epicenter of EQ.

If the increase in the amplitude of the signals received in Yakutsk on 10.05.13 was associated with seismic ionospheric disturbances above the epicenter, the increase in the amplitude of atmospherics received in Paratunka, Kamchatka region, from the same thunderstorm cells in general should be absent. Indeed, in the variations of amplitude of atmospherics in Paratunka received from the same azimuth as in Yakutsk $\left(110^{\circ}\right)$, on 10.05 .13 amplitude increases were not registered. At the same time, in the average amplitude of atmospherics received in Paratunka in the interval 11 - 16 UT (night) from the azimuth of $305^{\circ}$ corresponding to the azimuth to the epicenter of the $\mathrm{EQ}$, an increase was registered on 09.05.13 (Figure 4(c)). This confirms a possible connection of the increase 


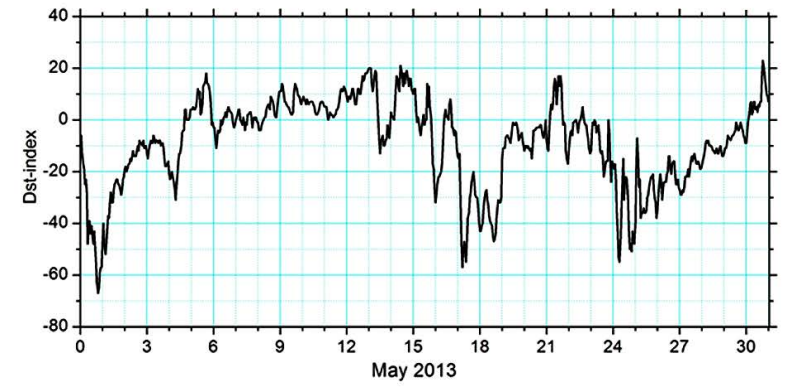

(a)

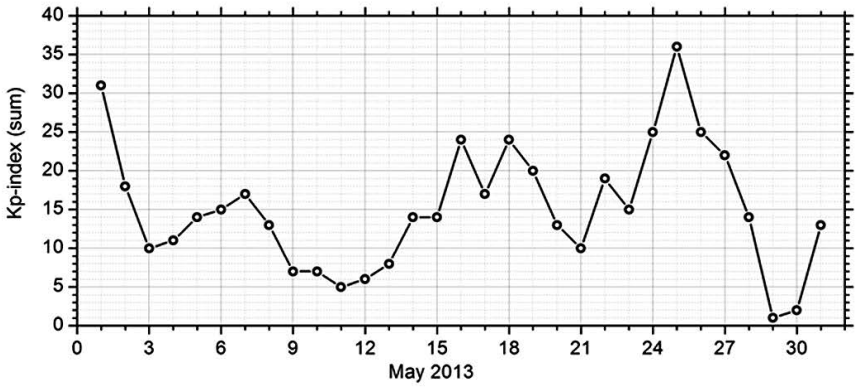

(b)

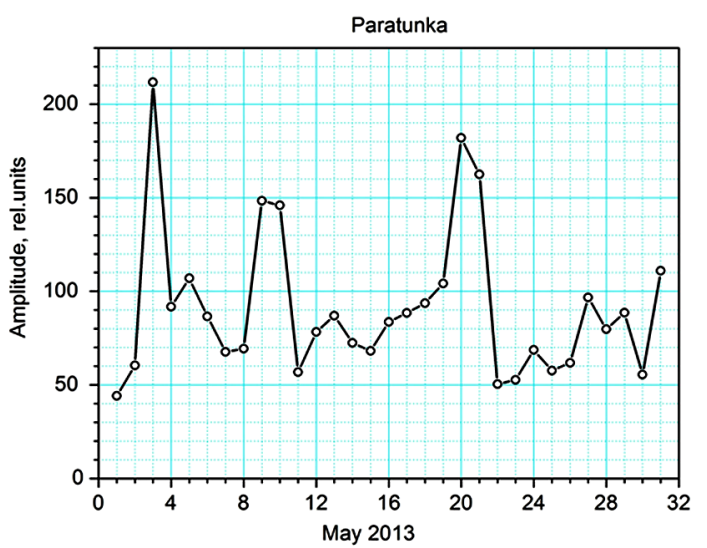

(c)

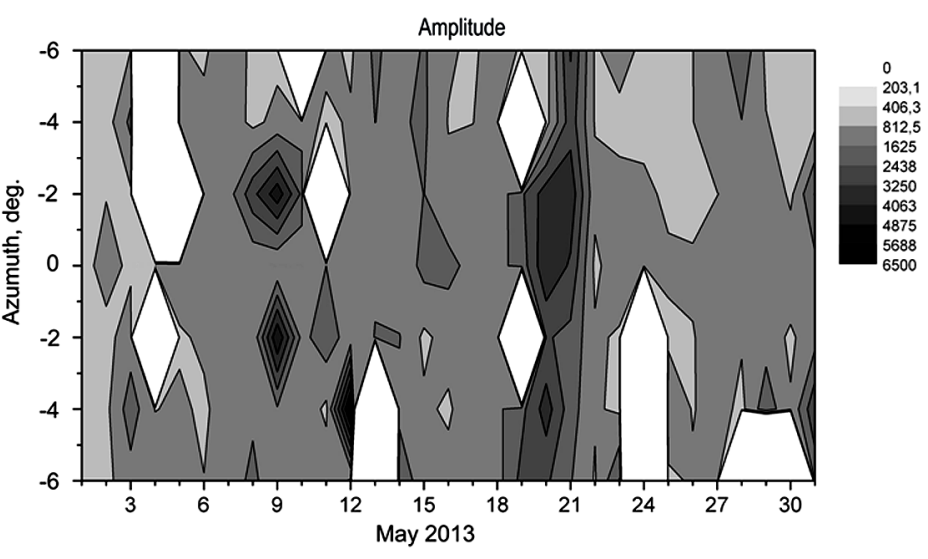

(d)

Figure 4. Variations of Dst-index (a) and Kp-index (b) in May 2013. The day-to-day variations of the average amplitude of atmospherics at 11 - 16 UT received in Paratunka from the azimuth to the epicenter of the EQ (c) and the azimuthal scan of amplitude variations of the atmospherics in the 12-deg. azimuthal sector centered to the epicenter direction (d).

of amplitude signals received in Yakutsk on 09-10.05.13 with lithospheric processes manifested later in the EQ of 24.05.13. Also, an increase in the amplitude of atmospherics in Paratunka was observed on 20-21.05.13. In addition, as seen in Figure 4(d), which shows the results of the azimuthal scan of amplitude variations of the atmospherics in the 12-deg. azimuthal sector centered to the epicenter direction, the increase of the amplitude on 09.05.13 has a focal character, but on 20-21.05.13 the amplitude increase was observed in the entire azimuth sector, though there was also maximum in the direction to the epicenter. It is noteworthy that in Paratunka the amplitude of atmospherics was not reduced to a single distance as in Yakutsk (attenuation of signal in the earthionosphere waveguide was not taken into consideration).

Taking into account the observations in Yakutsk, the focal disturbance near the direction to the epicenter allows us to associate it with great certainty with the lithospheric causes of disturbances in the ionosphere. A wide region of the amplitude disturbances of 20-21.05.13 corresponds to the results of observations of radio signals and atmospherics in Yakutsk and can apparently be explained by geomagnetic disturbances. At the same time, it is noteworthy that in the azimuthal scan of 20-21.05.13 (Figure 4(d)) there was a narrow sector of increased amplitude corresponding exactly to the direction to the epicenter. We can suggest that, in general, there were two precursors: on 09-10.05.13 and 20-21.05.13, but in the second precursor there probably was an effect of geomagnetic disturbances.

\section{CONCLUSION}

To detect seismic disturbances in the lower ionosphere, we have used the signals of very-low-frequency radio transmitters and natural radio signals-electromagnetic emission of lightning discharges - atmospherics. On earlier results of observation of atmospherics, it was obtained that the EQ effects are displayed as weight-hourly amplitude increases on the day of EQ or within 3 days after the events. Possible EQ precursors are also manifested as one-day (within one to several hours) increases in the amplitude of atmospherics on average 5 - 12 days before the event. Analysis shows that seismic effects in the amplitude of atmospherics have been observed in the case of sufficiently strong (magnitude $M>4.5$ ) and not very deep (usually no deeper than $50 \mathrm{~km}$ ) EQs. The effects of the events of the earthquake with magnitude of 8.2 occurring in the Sea of Okhotsk on 24.05.13 not far from the Kamchatka Peninsula at a depth of 609 km con- 
sidered in this work have shown that even deep EQs may have precursors in the form of disturbances in the lower ionosphere. EQs are often observed during periods of relatively strong geomagnetic disturbances. In the second precursor of the EQ under consideration, there probably was an effect of geomagnetic disturbances.

\section{ACKNOWLEDGEMENTS}

Some part of this research was conducted in the framework of Project 106 of SB of RAS.

\section{REFERENCES}

[1] Biagi, P.F., Castellana, L., Maggipinto, T., Piccolo, R., Minafra, A., Ermini, A., Martellucci, S., Bellecci, C., Perna, G., Capozzi, V., Molchanov O.A. and Hayakawa, M. (2005) A possible preseismic anomaly in the ground wave of a radio broadcasting $(216 \mathrm{kHz})$ during July-August 1998 (Italy). Natural Hazards and Earth System Sciences, 5, 727-732. http://dx.doi.org/10.5194/nhess-5-727-2005

[2] Biagi, P.F., Piccolo R., Ermini, A., Martelucci, S., Belecci, C., Hayakawa, M., Capozzi, V. and Kingsley, S.P. (2001) Possible earth-quake precursors revealed by LF radio signals. Natural Hazards and Earth System Sciences, 1, 99-104. http://dx.doi.org/10.5194/nhess-1-99-2001

[3] Biagi, P.F., Piccolo, R., Castellana, L., Ermini, A., Martelucci, S., Belecci, C., Capozzi, V., Perna, G., Molchanov, O. and Hayakawa, M. (2004) Variation in a LF radio signal on the occasion of the recent seismic and volcanic activity in Southern Italy. Physics and Chemistry of the Earth, 29, 551-557.

http://dx.doi.org/10.1016/j.pce.2003.10.005

[4] Hayakawa, M., Molchanov, O.A., Ondoh, T. and Kawai, E. (1996) The precursory signature effect of the Kobe earthquake on VLF subionospheric signals. Journal of Atmospheric Electricity, 16, 247-257.

[5] Hayakawa, M., Molchanov, O.A., Ondoh, T. and Kawai, E. (1996) Anomalies in the subionospheric VLF signals for the 1995 Hyogo-ken earthquake. Journal of Physics of the Earth, 44, 413-418. http://dx.doi.org/10.4294/jpe1952.44.413

[6] Rozhnoi, A., Solovieva, M., Molchanov, O., Biagi, P.-F., Hayakawa, M., Schwingenschuh, K., Boudjada, M. and Parrot, M. (2010) Variations of VLF/LF signals observed on the ground and satellite during a seismic activity in Japan region in May-June 2008. Natural Hazards and Earth System Sciences, 10, 529-534. http://dx.doi.org/10.5194/nhess-10-529-2010

[7] Liperovsky, V.A., Pokhotelov, O.A., Liperovskaya, E.V., Parrot, M., Meister, C.-V. and Alimov, A. (2000) Modification of sporadic E-layers caused by seismic activity. Surveys in Geophysics, 21, 449-486. http://dx.doi.org/10.1023/A:1006711603561

[8] Liperovskaya, E.V., Pokhotelov, O.A., Hobara, Y. and Parrot, M. (2003) Variability of sporadic E-layer semi transparency (foEs - fbEs) with magnitude and distance from earthquake epicenters to vertical sounding stations. Natural Hazards and Earth System Sciences, 3, 279-284. http://dx.doi.org/10.5194/nhess-3-279-2003

[9] Liperovsky, V.A., Meister, C.-V., Liperovskaya, E.V., Vasil'eva, N.E. and Alimov, O. (2005) On spread-Es effects in the ionosphere before earthquakes. Natural $\mathrm{Ha}$ zards and Earth System Sciences, 5, 59-62. http://dx.doi.org/10.5194/nhess-5-59-2005

[10] Mullayarov, V.A., Karimov, R.R. and Kozlov, V.I. (2007) Variations in thunderstorm VLF emissions propagating over the epicenters of earthquakes. Journal of Atmospheric and Solar-Terrestrial Physics, 69/13, 1513-1523. http://dx.doi.org/10.1016/j.jastp.2007.06.001

[11] Mullayarov, V.A., Abzaletdinova, L.M., Argunov, V.V. and Korsakov A.A. (2011) Variations in the parameters of thunderstorm electromagnetic signals on paths over earthquake regions. Geomagnetism and Aeronomy, 51, 825834. http://dx.doi.org/10.1134/S0016793211060120

[12] Mullayarov, V.A., Argunov, V.V., Abzaletdinova, L.M. and Kozlov, V.I. (2012) Ionospheric effects of earthquakes in Japan in March 2011 obtained from observations of lightning electromagnetic radio signals. Natural Hazards and Earth System Sciences, 12, 3181-3190. http://dx.doi.org/10.5194/nhess-12-3181-2012

[13] http://earthquake.usgs.gov

[14] www.wwlln.net 